\title{
Seasonal recruiting policies for table grape packing operations: A hybrid simulation modelling study
}

\author{
Mohammed Mesabbah \\ Technological University Dublin, mohammed.mesabbah@tudublin.ie \\ Siham Rahoui \\ Technological University Dublin, siham.rahoui@tudublin.ie \\ Mohamed AF Ragab \\ Technological University Dublin, mohamed.ragab@tudublin.ie
}

See next page for additional authors

Follow this and additional works at: https://arrow.tudublin.ie/ressupcon

Part of the Business Commons

\section{Recommended Citation}

M. Mesabbah, S. Rahoui, M. A. F. Ragab, A. Mahfouz and A. Arisha, "Seasonal recruiting policies for table grape packing operations: A hybrid simulation modelling study," 2017 Winter Simulation Conference (WSC), 2017, pp. 1680-1691, doi: 10.1109/WSC.2017.8247907.

This Conference Paper is brought to you for free and open access by the Supply Chain Management at ARROW@TU Dublin. It has been accepted for inclusion in Conference papers by an authorized administrator of ARROW@TU Dublin. For more information, please contact arrow.admin@tudublin.ie, aisling.coyne@tudublin.ie,gerard.connolly@tudublin.ie.

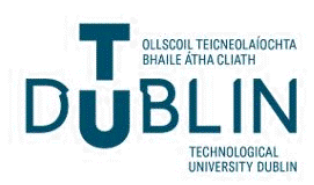


Authors

Mohammed Mesabbah, Siham Rahoui, Mohamed AF Ragab, Amr Mahfouz, and Amr Arisha

This conference paper is available at ARROW@TU Dublin: https://arrow.tudublin.ie/ressupcon/2 


\title{
SEASONAL RECRUITING POLICIES FOR TABLE GRAPE PACKING OPERATIONS: A HYBRID SIMULATION MODELLING STUDY
}

\author{
Mohammed Mesabbah \\ Siham Rahoui \\ Mohamed AF Ragab \\ Amr Mahfouz \\ Amr Arisha \\ 3S Group, College of Business \\ Dublin Institute of Technology (DIT) \\ Aungier St, Dublin 2, IRELAND
}

\begin{abstract}
The packing process is a critical post-harvesting activity in table grape industry. Workers in packing stations are hired under seasonal contracts because of product seasonality and operations labor intensity. Seasonal workers, however, are usually characterized by inconsistent performance, high turnover and experience variation which leads to low productivity and high waste. Few mathematical models were used for evaluating fresh products packing operations, but in a deterministic nature which hinders the complexity and dynamics of the business processes. Hence, a hybrid Discrete Event Simulation (DES) and Agent-Based Modelling (ABM) are employed to evaluate a set of seasonal recruiting policies in a large grape packing station. The paper aims to investigate the impact of workers experience on packing operations efficiency. The model outcomes demonstrate the improvement in operations efficiency and total running cost (about 20\% savings) that can be achieved when applying optimal recruiting policies that reduce labors variations.
\end{abstract}

\section{INTRODUCTION}

The current growth in the world population and the global economic development have resulted in a high demand on food products. In a competitive food markets, customers' requirements became stringent in terms of food safety, quality, and price. Table grape growers face the same challenges and they need to demonstrate high operational efficiency and effective supply chain cost strategies (Mesabbah et al. 2016). The packing process is a critical activity in the table grape supply chain and often involves series of activities including receiving, sorting, packing and storing grapes received from the vineyards. In order to perform these activities efficiently and in cost-effective way, high skilled workers are required to be recruited at the harvesting season (Blanco et al. 2005, Lambert et al. 2014).

The productivity of packing operations is intertwined with workers' accumulated experience and learned skills (Becker 2009). Although the relationship is intrinsic, little attention was given to the impact of workers experience on packing process performance. This raised many questions including; Does workers experience impact the overall productivity, quality, waste and total operational cost of packing operation? Do hiring policies play a role in improving business performance?

In order to address these questions, analytical models that simulate a grape packing station is developed to help decision-makers to investigate the impact of workers experience and labor hiring policies on the process productivity. However, the applications of these models on table grape 
supply chain are limited (Bohle, Maturana, and Vera 2010, Mesabbah et al. 2016). This paper therefore, presents a hybrid simulation model that integrates Discrete Event Simulation (DES) and Agent-based Modelling (ABM) to bridge this gap. The DES is used to model system's complexity and dynamics that cannot be modeled by deterministic mathematical models (Mittal and Krejci 2015). ABM on the other hand will explain the impact of the heterogeneous features of the packing process including labor seasonality and human experience (Higgins et al. 2010).

\section{LITERATURE REVIEW}

Improving packing processes in the fresh produce supply chains received extensive attention between practitioners and researchers alike. This is explained due to their role in protecting food products, extending shelf-life time and promoting attractiveness to customer (Sunk, Kuhlang, and Sihn 2015, Marsh and Bugusu 2007). Many articles discussed solutions to reduce packing cost, improve its performance, facilitate decision making and optimize planning activities (Jiao, 2012, Jiao, 2015). Transportation time from the vineyard to packing stations, resource planning and delivery costs are significant decisions that are evaluated in the literature using mathematical and simulation techniques (Ahumada and Villalobos 2011a). A discrete event simulation, for instance, was used to evaluate initiatives that reduce the waste in labor's working hours in a tomato greenhouse (Bechar et al. (2007). A stochastic and simulation model are combined in another study to optimize the recruiting practices for the seasonal workers in freshproduce supply chain and measure their impact on productivity and food wastage (Kim et al. 2013). In a similar study, the effect of hiring permanent staff on products packing performance in apple and pears farms has been investigated analytically by Blanco et al. (2005). Storage capacity of fruit palletization in South African has also been optimized using simulation optimization methodologies (Ortmann, Van Vuuren, and Van Dyk 2006).

Similar to the simulation approach, agent-based models are applied in various manufacturing and distribution contexts in order to improve the decision-making process (Nilsson and Darley 2006). However, there is no ABM applications in agri-fresh produce supply chain (AFPSC) have investigated the impact of labors recruitment policies and labor skills and experience on packing stations performance. Ahumada and Villalobos (2009) have also mentioned that using simulation approaches to plan and optimize AFPSC are underutilized comparing to the mathematical models. The activities in table grape industry is characterized by seasonality and encompass heterogeneous features that the mathematical models alone cannot model effectively. Therefore, a hybrid simulation model of DES and ABM can be a suitable methodology to model the heterogeneous characteristics in AFPSC, in particular labor experience and productivity (Mesabbah et al. 2016). The paper adopts a hybrid approach that integrates DES that depicts dynamics and complexities of packing operations and ABM that incorporates the heterogeneous characteristics of the seasonal workers. There is a general growing interest in the application of hybrid simulation approaches due to its capabilities to overcome the limitation of single approach solutions (Martinez-moyano and Macal 2016, Brailsford et al. 2013).

\section{TABLE GRAPE PACKING AND SEASONAL PACKERS ISSUE}

\subsection{Case Study - Ragab Farms}

Ragab Farms is a third-generation producer and exporter of premium fresh produce based in the North of Egypt. Stretching over 1700 acres of reclaimed desert land, the company has more than 300 employees and blends local competence with global expertise to export its fresh products to international markets. Ragab Farms manages a sizeable scale of operations which involve the production and management of ten thousand tons of produce. The table grapes division is one of the most important business units within the organization. It operates on 300 acres of land and produces 10 varieties of grapes, the majority of which are exported through the company's export subsidiary from Mid-May until the end of August.

The grapes packing process sits at the core of the export operation and determines, to a great extent, the efficiency of the supply chain and the quality of the final product. Once picked in the field, grapes are 
loaded in plastic crates and transported by truck to the packing station. The fruit is offloaded in an airconditioned receiving area, then is carried by conveyors along packing lanes to be packed by labor into 500 gram punnets which would be ultimately sold to retail consumers. Packing process relies entirely on the manual skill of the packing labor who work in groups of two to three on packing tables. In addition to packing the fruit into the punnets, their other tasks include: 1) Visually inspecting the fruits, 2) Removing any defective berries, 3) Adjusting the weight of each punnet using a digital scale, and 4) Stacking each ten punnets into one $5 \mathrm{~kg}$ box. Accordingly, their role has a major impact on a number of performance indicators including productivity, fruit wastes, and quality of the final product.

The hybrid model developed represents the packing operations for received quantities from the vineyards over five weeks (from $12^{\text {th }}$ May to $18^{\text {th }}$ June). Packing station under study comprises four packing lines, each line has a set of packing tables where packers are assigned to perform packing activities. The maximum number of tables in the station that can operate simultaneously is 95 . Each packing table can operate with two or three packers according to the work volumes. Daily received quantities (in tons) can vary according to harvesting conditions (Figure 1).

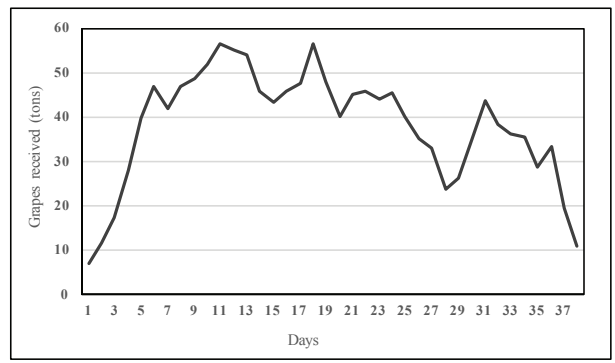

Figure 1. Daily Received Quantity from the vineyards 2016.

\subsection{Problem Definition}

The biological deterioration of table grapes starts directly after harvesting (Nagasawa, Kotani, and Morizawa 2009). The packing quality plays instrumental role in preserving grape quality and freshness during distribution activities (Blanco et al. 2005). In Ragab Farms, grapes are transported from the vineyards to the packing station in a daily basis. Packing stations managers provide extra attention to two main issues during operations; first, the packing process must start directly, with no delay, after receiving grape from the vineyard. Reducing the waiting time of the grape in the receiving area helps to preserve products quality and shelf-life time. Second, it is important to maintain grape waste in its minimum level by developing packers skills and maintain the most experienced one. Employing efficient recruitment plans and optimizing labors capacity play key roles in achieving both objectives.

During 2016, the packing station at Ragab farm received around 1500 tons of grapes. Only 1250 tons were packed as final products and 250 tons $(17 \%)$ were considered waste. In addition, the average waiting time of the grape in the receiving area, during the season peak, estimated by 24 hours in average. It is believed that improving packers skills and preserving their experience is important to improve farm's performance and productivity.

During the harvesting seasons, packers are recruited on a daily basis based on managers' demand. The recruiting process is basically relying on the seasonal workers from nearby rural areas. However, the fierce competition between growers to recruit skillful workers affects the consistency of workers supply. In addition, recruiting agencies cannot guarantee to supply the same group of labors every day because of the seasonality nature of the process. However, hiring the same packers reduce training efforts and reflect positively on farm's productivity and product quality. 


\section{HYBRID MODEL DEVELOPMENT}

The developed hybrid model allows managers to evaluate different hiring policies for the seasonal packers in Ragab Farm's. It helps farm's managers to select the best hiring policy that can retain experienced packers over the harvesting season and investigate how this impacts labor productivity, hiring costs, losses costs, and operational efficiency. The model consists of five building blocks as shown in Figure 2.

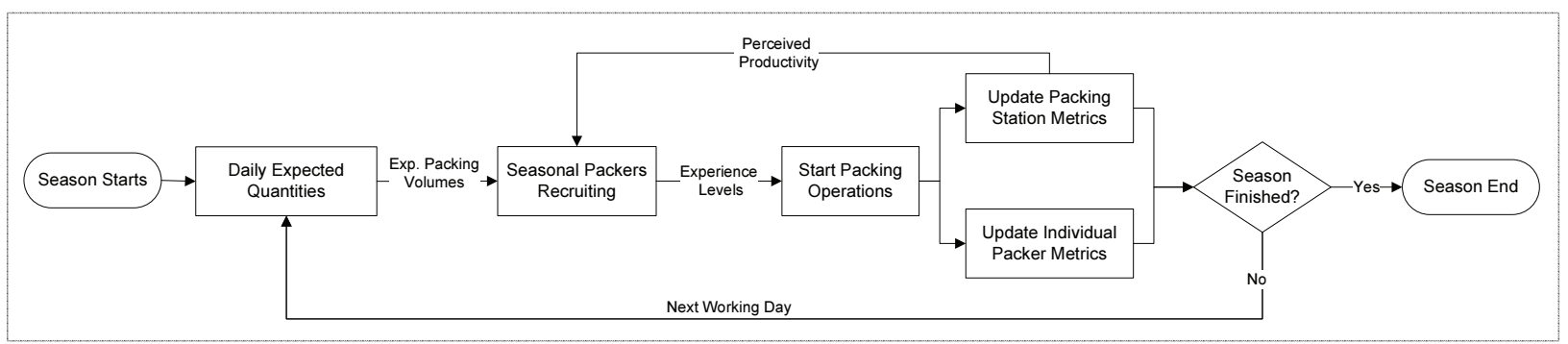

Figure 2. Model Building Blocks.

At the start of harvesting season, manager of packing station receives rough estimates of the expected harvest quantities that can be received at the station. "Daily Expected Quantities" block is responsible of predicting harvest quantities based on the historical data of the previous seasons (Figure 1). The number of required packers is then estimated based on packers' productivity rate and the expected quantities of harvested grapes. The "Seasonal Packers Recruiting" block simulates the hiring process of the seasonal packers. The packing processes are then modeled in the "Start Packing Operations" block and contains the planning of resources capacity, processes structure, and the relationships between system's parameters. The discrete event simulation is used to model the business processes and their dynamics, while the human and equipment in the station are modeled as agents - highlighted in yellow in Figure 3. At the end of every working day, the performance metrics of packing station are updated - "Update Packing Station Metrics" block - as well as each packer agent metrics - "Update Individual Packer Metrics".

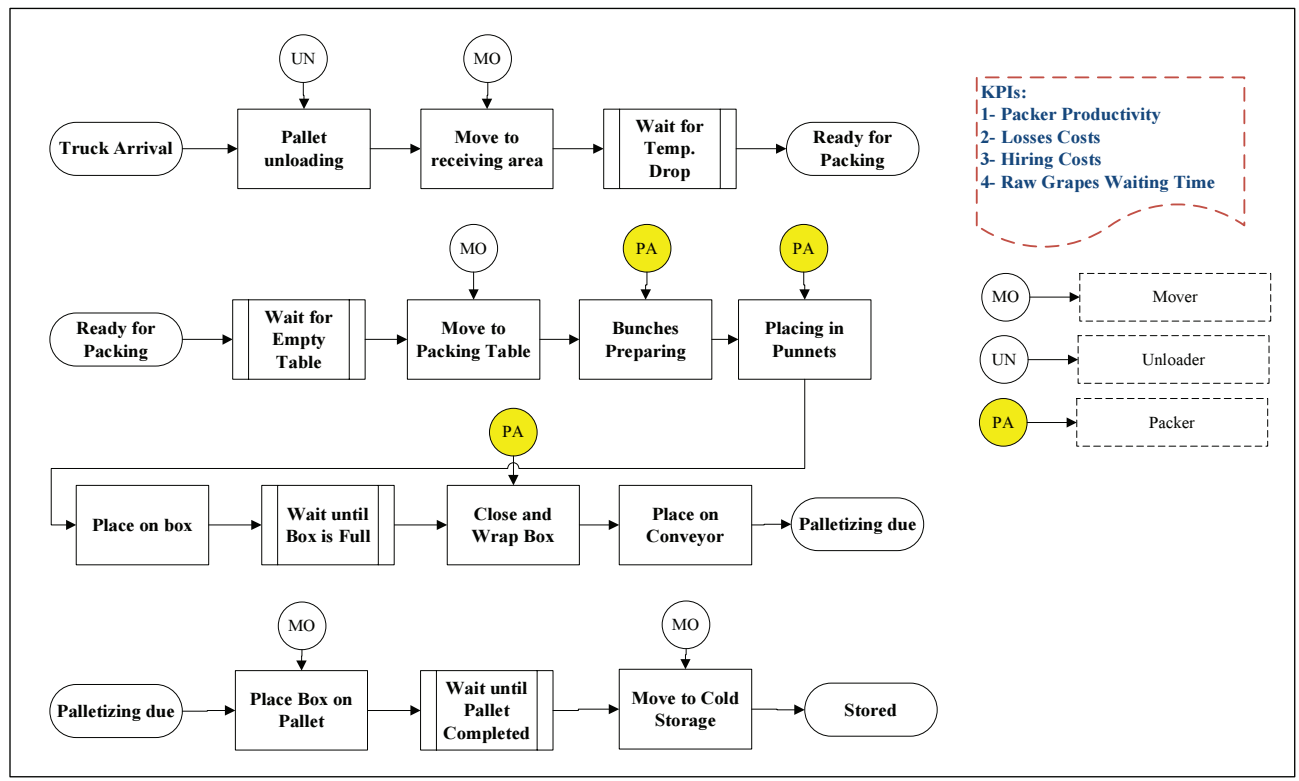

Figure 3. Conceptual Model for Packing Station Operations. 


\subsection{Mathematical Formulation}

Block 1: Daily Expected Quantities to arrive at the packing station $(\widehat{\boldsymbol{Q}})$ are the main factors that controls the number of packers to be recruited at any particular day. This quantity is calculated based on historical figure for the daily received quantities using the following equation:

$$
\hat{Q}(t)=\tilde{Q}(t) \cdot(1+w)
$$

Where, $\boldsymbol{t}$ is simulation time (days), $\tilde{Q}$ is historical quantity received at the corresponding simulation day and $w$ is simple random noise between -0.15 and 0.15 , to reflect the reality when estimated quantity is deviated from actual one.

Block 2: Seasonal Packers Recruiting The number of packers $\left(\boldsymbol{N}_{\boldsymbol{P}}\right)$ required to pack this quantity is calculated using the following equation:

$$
\boldsymbol{N}_{\boldsymbol{P}}(t)=\frac{\hat{Q}(t)+Q_{u}(t-1)}{P(t)}
$$

Where, $\boldsymbol{Q}_{\boldsymbol{u}}$ is the unpacked raw grapes from the previous day (if any), and $\boldsymbol{P}$ is the perceived packer productivity at day $\boldsymbol{t}$. Packers' productivity is a updated in “Update Packing Station Metrics” block.

Block 3: Start Packing Operations is triggered by the arrival of harvested grape in the receiving area. Grape pallets are unloaded and placed in the receiving area for a while to allow the cooling down of product temperature before the start of packing operations. Afterwards, grapes pallets are moved to the packing area, then the crates are distributed over the packing tables according to their availability. Once a crate is placed on a packing table, the packers pick the grape bunches and perform three main processes as illustrated in agents' state chart in Figure 4: 1) Preparing_Bunch to remove any damaged and/or inconsistent berries; 2) Packing_Punnet where bunches are cut and placed in $0.5 \mathrm{~kg}$ weighted plastic punnet, then it is placed in a packing box; once the box becomes full (it takes 10 punnets); 3) Wrapping_Box process take place. Any packer At_Packing_Table can do any of these processes.

The times for these processes along with the quantities of products waste vary from packer to another according to the experience level. This experience represents the skills that a packer gains either over the current season or previously if she was recruited before. Packers' experience level along with packing cycle times and grapes waste fractions - which both are functions of packer experience - are updated in Update Individual Packer Metrics” block. Once the work is finished, the performance metrics of packing station and packers are updated.

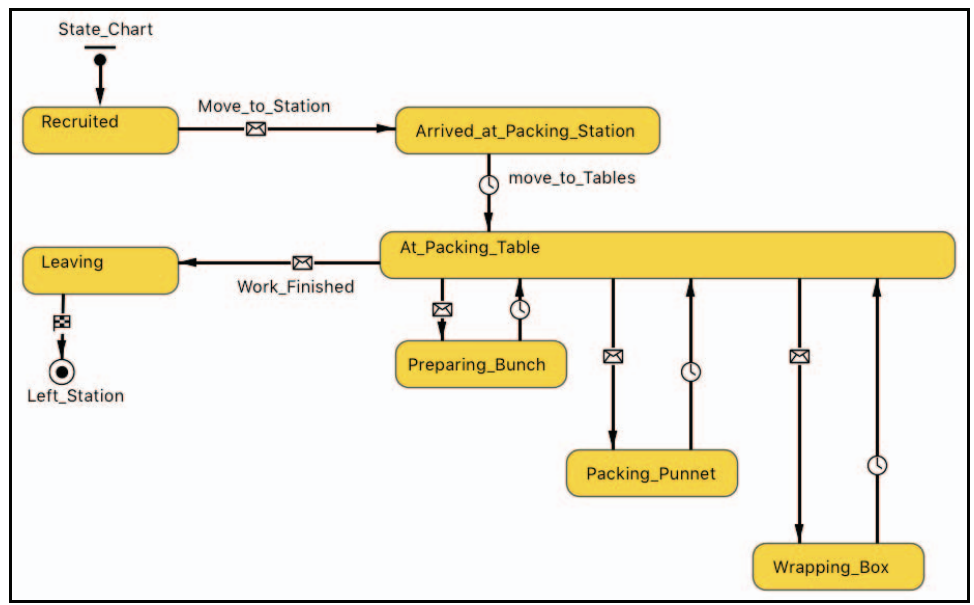

Figure 4. Seasonal Packer State Chart 
Block 4: Update Packing Station Metrics block focuses on a set of operational metrics that include: 1) daily packed quantity $\left.\left(\boldsymbol{Q}_{\boldsymbol{p}}\right) ; 2\right)$ grapes loss quantity $\left.\left(\boldsymbol{Q}_{\boldsymbol{l}}\right) ; 3\right)$ unpacked quantity $\left(\boldsymbol{Q}_{\boldsymbol{u}}\right)$; 4) Average waiting time for packing $(\boldsymbol{A W T})$; 5) grapes loss cost $\left.\left(\boldsymbol{C}_{\boldsymbol{L}}\right), 6\right)$ packers hiring cost $\left.\left(\boldsymbol{C}_{\boldsymbol{P}}\right), 7\right)$ perceived worker productivity $(\boldsymbol{P})$. These metrics are updated according to the following set of equations:

$$
Q_{p}(t)=Q_{b}(t) \cdot b_{w}
$$

Where $\boldsymbol{Q}_{\boldsymbol{b}}$ is number of packed boxes and $\boldsymbol{b}_{\boldsymbol{w}}$ is packed box weight (which is $5 \mathrm{~kg}$ ).

$$
\begin{aligned}
& Q_{l}(t)=Q_{h}(t)-Q_{p}(t) \\
& Q_{u}(t)=Q_{r}(t)-Q_{h}(t)
\end{aligned}
$$

Where $\boldsymbol{Q}_{\boldsymbol{h}}$ is the handled quantity, which actually moved from receiving area to packing area and $\boldsymbol{Q}_{\boldsymbol{r}}$ is the received quantity from the vineyards at that day.

$$
\begin{aligned}
& C_{L}(t)=l_{c} \cdot Q_{l}(t) \\
& C_{P}(t)=p_{c} \cdot N_{P}(t)
\end{aligned}
$$

Where $\boldsymbol{l}_{\boldsymbol{c}}$ is grapes loss cost per ton and $\boldsymbol{p}_{\boldsymbol{c}}$ is hiring cost per packer per day.

$$
P(t)=\operatorname{Delay}_{1}(P(0), \bar{P}(t), a)
$$

Where $\left(\boldsymbol{D e l a y}_{\mathbf{1}}\right)$ is first order delay function introduced by Sterman $(2000), \boldsymbol{P}(\mathbf{0})$ is the initial value for the perceived packer productivity and $\boldsymbol{a}$ is time to adjust perceived productivity and $\overline{\boldsymbol{P}}$ is average packer productivity that can be calculated as following:

$$
\bar{P}(t)=\frac{Q_{h}(t)}{N_{P}(t)}
$$

Average waiting time for packing $(\boldsymbol{A W T})$ is tracked based on the difference between the time that a raw pallet becomes ready for packing $\left(\boldsymbol{T} \boldsymbol{p}_{\boldsymbol{r}}\right)$ and the time it is moved to packing area $\left(\boldsymbol{T} \boldsymbol{p}_{\boldsymbol{m}}\right)$. This time difference is accumulated for all the pallets received and divided by total number of raw pallets handled to the current day $(\boldsymbol{t})$. Therefore $\boldsymbol{A W T}$ can be formulated as following:

$$
A W T(t)=\frac{\sum_{i=0}^{\text {total pallet handled }}\left(T p_{m_{i}}-T p_{r_{i}}\right)}{\text { total pallet handled }}
$$

Block 5: Update Individual Packer Metrics block updates metrics for each recruited packer. The model assumes a pool of seasonal packer available for recruiting with size notated as $\left(\mathbf{N}_{\mathbf{S}}\right)$. There are mainly two metrics to be updated in this block: 1) number of working days $(\boldsymbol{D})$ and 2) experience level (E). The number of working days for each packer is updated as following:

$$
D_{i}(t)=\left\{\begin{array}{cc}
D_{i}(t-1)+1, & \text { if packer } i \text { is recruited at day } t \\
D_{i}(t-1), & \text { Otherwise }
\end{array} \quad \forall i=1,2, \ldots, \mathrm{N}_{\mathrm{S}}\right.
$$

The concept of continuous improvement and learning curves introduced by Zangwill and Kantor (1998) is used to model updating packer's experience level using the following equation:

$$
E_{i}(t)=\min \left(E^{m}, E_{i}(0) \cdot e^{r \cdot D_{i}(t)}\right) \quad \forall i=1,2, \ldots, \mathrm{N}_{\mathrm{S}}
$$


Where $\boldsymbol{r}$ is a learning curve parameter, $\boldsymbol{E}(\mathbf{0})$ is the initial experience level and $\boldsymbol{E}^{\boldsymbol{m}}$ is the maximum experience level. Next section discusses data collected for this model as well as the developed statistical distributions of loss fractions and times of the main packing processes for each packer.

\subsection{Data Collection}

The primary data in this research are collected based on: 1) historical data based on season 2016; 2) series of interviews with the packers along with the station managers; and 3) On-site observations for packing and handling processes. Table 1 illustrates model parameters and their description, sources of data and their equations.

Table 1: Model Parameters

\begin{tabular}{|c|c|c|c|}
\hline PARAMETER & Description & Eq. \# & Source \\
\hline$N_{U}$ & Number of unloaders at the station & & Site observations \\
\hline$N_{M}$ & Number of movers at the station & & Site observations \\
\hline$N_{T}$ & Number of packing tables at the station & & Site observations \\
\hline$b_{w}$ & Packed box weight & 3 & Internal records \\
\hline$l_{c}$ & Cost for grape losses per ton & 6 & Internal records \\
\hline $\boldsymbol{p}_{c}$ & Hiring cost per packer per day & 7 & Internal records \\
\hline $\mathbf{N}_{\mathbf{S}}$ & Number of seasonal packers in nearby rural areas & 11,12 & Manager Judgments \\
\hline$P(\mathbf{0})$ & Initial perceived worker's productivity & 8 & Manager Judgments \\
\hline$a$ & Time to adjust worker's productivity & 8 & Manager Judgments \\
\hline$m_{p r_{\max }}, \boldsymbol{m}_{p r_{\min }}$ & Mean time to preparing bunch for least and most experienced packers respectively & & Site observations \\
\hline $\boldsymbol{m}_{p p_{\max }}, \boldsymbol{m}_{p p_{\min }}$ & Mean time to packing punnet for least and most experienced packers respectively & & Site observations \\
\hline $\boldsymbol{m}_{w_{\max }}, \boldsymbol{m}_{w_{\min }}$ & Mean time to wrapping box for least and most experienced packers respectively & & Site observations \\
\hline$l_{\text {max }}, l_{\min }$ & Mean loss fraction resulted by least and most experienced packers respectively & & Site observations \\
\hline $\boldsymbol{r}$ & learning curve parameter & 12 & Assumption \\
\hline $\boldsymbol{E}^{m}$ & The maximum experience level for seasonal worker & 12 & Assumption \\
\hline OTHER & Mean time for the other processes (e.g., pallets unloading) in Figure 3 & & Site observations \\
\hline
\end{tabular}

To reflect the variations in packers' experience, the model initializes each packer with random experience level $(\boldsymbol{E}(\mathbf{0}))$ between $\mathbf{1}$ and $\mathbf{5}$ at the start of the season (where 5 means the highest experience level). The statistical analysis of the processing time data of the three packing processes indicates that Preparing_Bunch, Packing_Punnet and Wrapping_Box processing time are distributed as Lognormal distribution with standard deviation equals to $0.5,0.5$ and 0.25 respectively. The mean processing time of the three processes vary from packer to another based on the experience level. They are estimated by comparing the performance of the lowest experienced packers at the beginning of the season against their performance at the end of season, the results are presented in Table 2.

A similar analysis was conducted to drive the statistical distribution of Loss_Fraction parameter for the least and the most experienced packer. It was found that the Loss_Fraction of any packer follows Normal distribution with a standard deviation 0.02 and mean value varies according to packers' experience level (Table 2). Finally, the model assumes linear relationship between packer's experience level and means of the statistical distributions as illustrated in Figure 5.

Table 2: Mean Values for the Statistical Distributions for Least and Most Experienced Packers

\begin{tabular}{|l|l|l|}
\hline & \multicolumn{1}{|c|}{ Least Experienced } & \multicolumn{1}{c|}{ Most Experienced } \\
\hline PREPARING_BUNCH & $\boldsymbol{m}_{\boldsymbol{p r}}=3.40$ & $\boldsymbol{m}_{\boldsymbol{m} r_{\text {min }}}=2.30$ \\
PACKING_PUNNET & $\boldsymbol{m}_{\boldsymbol{p} \boldsymbol{p}_{\max }}=3.1$ & $\boldsymbol{m}_{\boldsymbol{p} p_{\min }}=2.07$ \\
WRAPPING_BOX & $\boldsymbol{m}_{\boldsymbol{w}_{\max }}=3.52$ & $\boldsymbol{m}_{\boldsymbol{w}_{\min }}=2.99$ \\
LOSSES_FRACTION & $\boldsymbol{l}_{\max }=0.2$ & $\boldsymbol{l}_{\min }=0.05$ \\
\hline
\end{tabular}




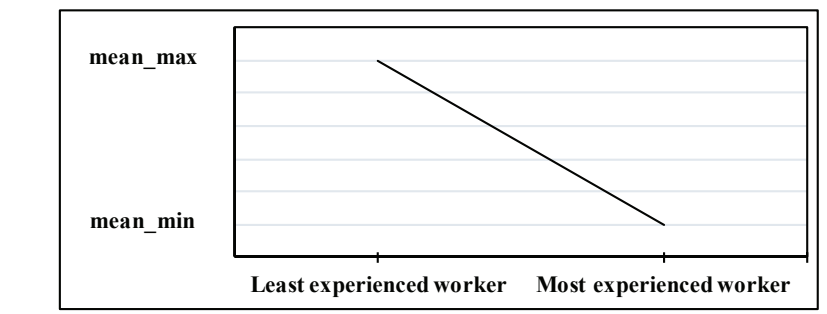

Figure 5. Worker's experience Relationship with distributions means

\section{OPERATIONAL IMPLICATIONS}

The main objective of the model is to investigate different recruiting policies for the seasonal grape packers and try to understand how these policies impact packing station performance. To achieve this objective three different scenarios are evaluated using the hybrid simulation model.

Under business as usual policy $(\boldsymbol{B} \boldsymbol{A} \boldsymbol{U})$ the unit manager decides how many packers $\left(\boldsymbol{N}_{\boldsymbol{P}}\right)$ to recruit at any particular day based on the expected quantity of harvested grapes in the receiving area. Workers agencies secure the required number of packers, but that does not imply calling for the trained packers again to the station. They claim that the variability in the required number of packers and market demands can influence their ability to supply same packers every day.

The First proposed policy (P1) tries to resolve this issue by offering extra hiring cost (25\%) per packer $\left(\boldsymbol{p}_{\boldsymbol{c}}\right)$ under a condition that worker agency secure the required number of packers where the priority is given to the packers who worked previously in the station. On the other hand, the managers under the second policy (P2) will recruit a fixed number of packers over the season (i.e., $\boldsymbol{N}_{\boldsymbol{P}}$ will be constant). In this scenario the recruiter will be incentivized to bring the same people every day.

It is noted that the impact of reducing recruitment variations of packers reflects the development of packer's experience level significantly under the three policies (Figure 6.a). Hiring same packers (under $\boldsymbol{P 2}$ ) or the most recruited ones (under P1) at the station allows rapid development of the packers experience level on both individual and collective levels, which reduce the packing processing times. As a result this positively impacts packers' productivity and, hence, number of packers needed, this is the case in $\boldsymbol{P} \mathbf{1}$ compared to $\boldsymbol{B} \boldsymbol{A U}$ (Figures 6.b and 6.c). However, in $\boldsymbol{P} \mathbf{2}$ the productivity collapses after nearly two weeks. This can be justified in light of equation (9) where number of packers $\left(\boldsymbol{N}_{\boldsymbol{P}}\right)$, the denominator, is fixed at the same time that daily receiving quantity is decreasing (and consequently the handled quantity $\left(\boldsymbol{Q}_{\boldsymbol{h}}\right)$, the numerator) as presented in Figure 1.

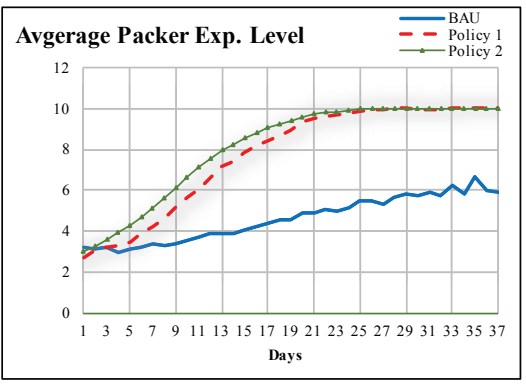

(a)

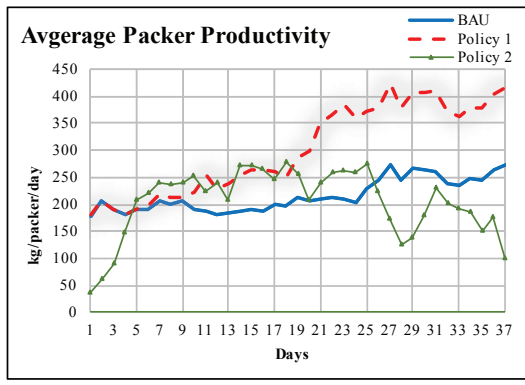

(b)

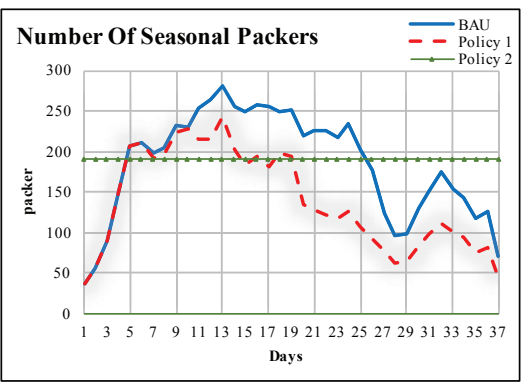

(c)

Figure 6. Average Packer Experience level and Productivity and Number of Packers recruited under the three scenarios

More positive implications of the proposed policies can be observed when considering their impact on grape waste during packing (Figure 7.a). Although it is not a significant difference, but Figure 7.a suggests that $\boldsymbol{P} \mathbf{2}$ is performing better than $\boldsymbol{P} \mathbf{1}$ on saving grape waste. This can be justified in the light of Figure 6.a, where rate of experience improving is slightly higher under $\boldsymbol{P} \mathbf{2}$ compared to $\boldsymbol{P} \mathbf{1}$ because all packers are hired consistently every working day over season. On the other hand, $\boldsymbol{P} \boldsymbol{1}$ shows improvement 
in reducing grapes waiting time compared to $\boldsymbol{P} \mathbf{2}$ which is not better than $\boldsymbol{B} \boldsymbol{A U}$ in this regard (Figure 7.b). The flexibility in the number of recruited packers in $\boldsymbol{P 1}$ concurrently with their improved experience helped in quicker reduction for accumulated unpacked grapes during season peak (Figure 1).

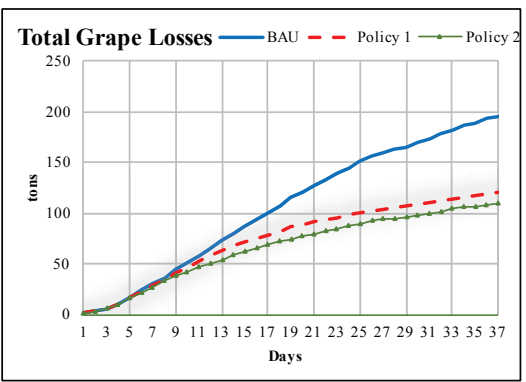

(a)

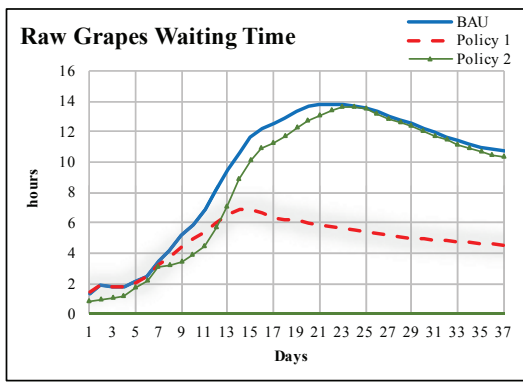

(b)

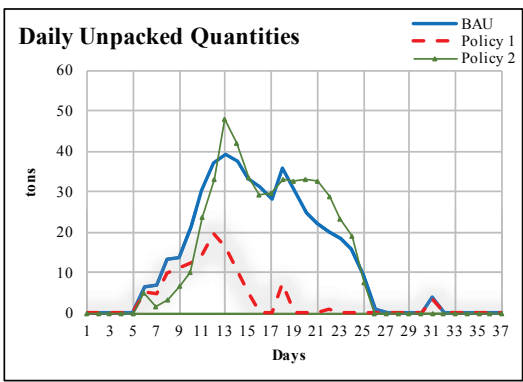

(c)

Figure 7. Total Grapes Losses, Raw Grapes Waiting time and Daily Unpacked Quantities under the three scenarios

from the financial perspective, the proposed policies can show significant improvement in the total operation costs compared to $\boldsymbol{B} \boldsymbol{A} \boldsymbol{U}$ policy (Figure 8.c). However, the results indicate that none of the two policies outperforms the other based on the total operational costs. The reason is that because each policy outperforms the other in cost saving over one of the two cost elements (losses costs and hiring costs) and the magnitude of these savings are almost the same (Figure 8.a and 8.b).

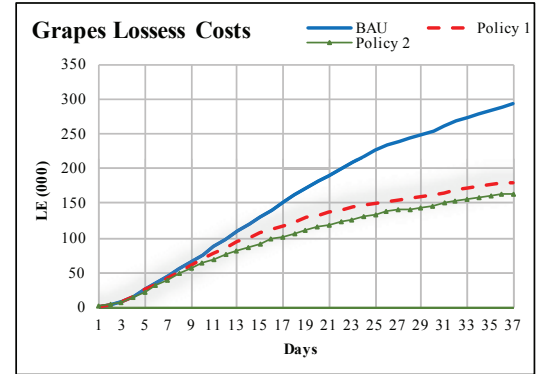

(a)

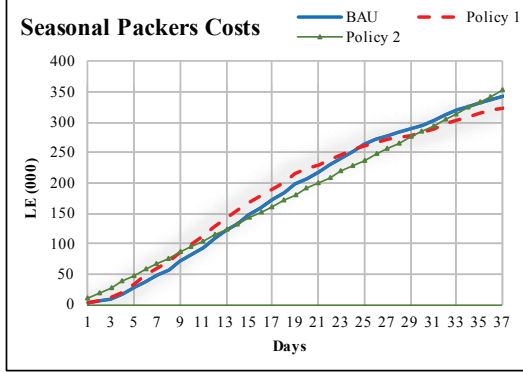

(b)

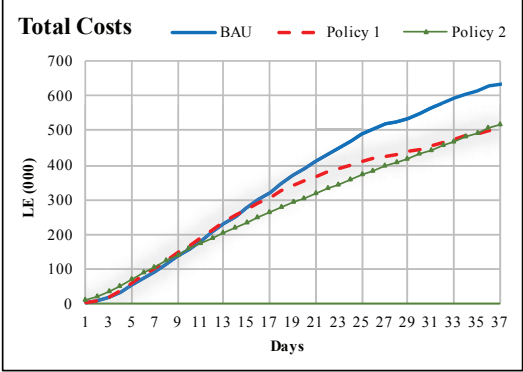

(c)

Figure 8. Total Grapes Losses, Total Costs and Seasonal Packers Costs under the three scenarios

\section{CONCLUSIONS}

The hybrid model suggests that if significant and sustainable improvement is to be achieved in the packing processes of table grape, it has to be in recruiting policies. Primarily to retain experienced workers while considering the impact of this decision on the financial performance. While analytical approaches such as mathematical, simulation and optimization models can support decisions, using an integration solution seem to offer more agile model that is capable to simulating complexity of dynamic relationship in table grape applications. Hybridization of ABM and DES has proven effective in gaining insights of grape packing station through simulating the process activities before evaluating operational strategies and related decisions.

Results have showed that the applied recruiting policy (BAU) in Ragab Farms is less efficient comparing to the two new policies (i.e. $\boldsymbol{P} \mathbf{1}$ and $\boldsymbol{P}$ ). $\boldsymbol{P 1}$ demands offering experienced workers higher wages because the model outcomes have justified the financial obligations for the return on labor productivity and cycle time reduction. While, $\boldsymbol{P} \mathbf{2}$ calls for a constant number of packers to be hired every day during the whole season. This policy has a significant improvement in reducing wastes of grapes as a result of the build-up experience and training from first day on site.

The model results are well-received by the packing station management team. They appreciate the managerial insights gained and applicability of the model to examine different operational strategies and 
improvement initiatives. Decision to retain experienced workers is what management sought to implement.

Potential future work may include integrating system dynamics approach to the hybrid model in order to support strategic decisions in grape industry (e.g. capital investments, marketing policies and global distribution). There is also an opportunity to extend the model and consider other post-harvesting functions such as receiving and storing operations.

\section{REFERENCES}

Ahumada, Omar, and J. Rene Villalobos. 2009. "Application of planning models in the agri-food supply chain: A review." European Journal of Operational Research 196 (1):1-20.

Ahumada, Omar, and J. Rene Villalobos. 2011a. "Operational model for planning the harvest and distribution of perishable agricultural products." International Journal of Production Economics 133 (2):677-687.

Ahumada, Omar, and J. Rene Villalobos. 2011b. "A tactical model for planning the production and distribution of fresh produce." Annals of Operations Research 190 (1):339-358.

Ainsworth, Susan, and Alice Purss. 2009. "Same time, next year?" Personnel Review 38 (2):217-235.

Bechar, A., S. Yosef, S. Netanyahu, and Y. Edan. 2007. "Improvement of Work Methods in Tomato Greenhouses Using Simulation." Transactions of the ASABE 50 (2).

Becker, Gary S. 2009. Human capital: A theoretical and empirical analysis, with special reference to education: University of Chicago Press.

Blanco, A. M., G. Masini, N. Petracci, and J. A. Bandoni. 2005. "Operations management of a packaging plant in the fruit industry." Journal of Food Engineering 70 (3):299-307.

Bohle, Carlos, Sergio Maturana, and Jorge Vera. 2010. "A robust optimization approach to wine grape harvesting scheduling." European Journal of Operational Research 200 (1):245-252.

Brailsford, Sally C, Joe Viana, Stuart Rossiter, Andrew Channon, and Andrew J Lotery. 2013. "Hybrid simulation for health and social care: the way forward, or more trouble than it's worth?" In 2013 Winter Simulations Conference (WSC):edited by R. Pasupathy, S.-H. Kim, A. Tolk, R. Hill, and M. E. Kuhl, 258-269. IEEE.

Deng, L, R Wang, T Dong, J Feng, and M Weisong. 2016. "Assessing the table grape supply chain performance in China - a value chain analysis perspective." British Food Journal 118 (5):1129-1145.

Ferrer, Juan Carlos, Alejandro Mac Cawley, Sergio Maturana, Sergio Toloza, and Jorge Vera. 2008. "An optimization approach for scheduling wine grape harvest operations." International Journal of Production Economics 112 (2):985-999.

Higgins, A., G. Antony, G. Sandell, I. Davies, D. Prestwidge, and B. Andrew. 2004. "A framework for integrating a complex harvesting and transport system for sugar production." Agricultural Systems 82 (2):99-115.

Higgins, A. J., C. J. Miller, A. A. Archer, T. Ton, C. S. Fletcher, and R. R. J. McAllister. 2010. "Challenges of operations research practice in agricultural value chains." Journal of the Operational Research Society 61 (6):964-973.

Jiao, W, Z Fu, W Mu, X Zhang, J Lu, and M Xu. 2015. "Estimating technical efficiency of Chinese table grape wholesalers." British Food Journal 117 (6):1670-1688.

Jiao, Weihua, Zetian Fu, Weisong Mu, Neil McLaughlin, and Mark Xu. 2012. "Influence of supply chain model on quality and safety control of table grape and performance of small-scale vinegrowers in China." British Food Journal 114 (7):978-996.

Kim, Kilhwan, Tae-Sung Kim, Dae-Eun Lim, and Hyun Min Park. 2013. "Managing the supply and demand uncertainty in workforce recruitment: planned or just-in-time acquisition." The Journal of the Operational Research Society 64 (11):1654-1663.

Lambert, G. F., A. A. A. Lasserre, M. M. Ackerman, C. G. M. Sánchez, B. O. I. Rivera, and C. AzzaroPantel. 2014. "An expert system for predicting orchard yield and fruit quality and its impact on the Persian lime supply chain." Engineering Applications of Artificial Intelligence 33:21-30. 
Lee, S.G., and S.W. Lye. 2003. "Design for manual packaging." International Journal of Physical Distribution \& Logistics Management 33 (2):163-189.

Marsh, Kenneth, and Betty Bugusu. 2007. "Food packaging - Roles, materials, and environmental issues: Scientific status summary." Journal of Food Science 72 (3):39-55.

Martinez-moyano, Ignacio J, and Charles M Macal. 2016. "A Primer for Hybrid Modeling and Simulation."133-147.

Mesabbah, Mohammed, Amr Mahfouz, Mohamed A F Ragab, and Amr Arisha. 2016. "Hybrid modeling for vineyard harvesting operations." In 2016 Winter Simulations Conference (WSC):edited by T. M. K. Roeder, P. I. Frazier, R. Szechtman, E. Zhou, T. Huschka, and S. E. Chick, 1642-1653. IEEE.

Miller, W.a., L.C. Leung, T.M. Azhar, and S. Sargent. 1997. "Fuzzy production planning model for fresh tomato packing." International Journal of Production Economics 53 (3):227-238.

Mittal, Anuj, and Caroline C. Krejci. 2015. "A hybrid simulation model of inbound logistics operations in regional food supply systems." In 2015 Winter Simulations Conference (WSC):edited by L. Yilmaz, W. K. V. Chan, I. Moon, T. M. K. Roeder, C. Macal, and M. D. Rossetti, 1549-1560. IEEE.

Nagasawa, H., M. Kotani, and K. Morizawa. 2009. "Optimal Cooperative Harvesting Patterns of Agricultural Fresh Products in Case of Multiple Farmers and Multiple Markets under Periodical Flowering." Journal of the Operations Research Society of Japan 52 (4):417-432.

Nilsson, Fredrik, and Vince Darley. 2006. "On complex adaptive systems and agent-based modelling for improving decision-making in manufacturing and logistics settings: Experiences from a packaging company." International Journal of Operations \& Production Management 26 (12):1351-1373.

Ortmann, Frank G, JH Van Vuuren, and FE Van Dyk. 2006. "Modelling the South African fruit export infrastructure: A case study." ORiON 22 (1):35-57.

Sterman, John D. 2000. Business dynamics: systems thinking and modeling for a complex world. Vol. 19: Irwin/McGraw-Hill Boston.

Sunk, A., Peter Kuhlang, and Wilfried Sihn. 2015. "Improving Productivity By Deriving and Defining." Transactions of FAMENA 39 (3):35-46.

Xu, Rui, Fumiomi Takeda, Gerard Krewer, and Changying Li. 2015. "Measure of mechanical impacts in commercial blueberry packing lines and potential damage to blueberry fruit." Postharvest Biology and Technology 110:103-113.

Zangwill, W. I., and P. B. Kantor. 1998. "Toward a theory of continuous improvement and the learning curve." Management Science 44 (7):910-920.

\section{AUTHOR BIOGRAPHIES}

MOHAMMED MESABBAH, M.Sc. is a researcher in 3S Group (A research unit specialized in simulation and optimization of complex business processes) in College of Business - Dublin Institute of Technology (DIT)). He joins the 3S Group in 2013. He holds a B.Sc. degree in Operations Research and decision support from Cairo University and M.Sc. in System Dynamics from University of Bergen. His research interests include Decision Support, Modeling and Simulation, Optimization, Computational intelligence and Game Theory. mohamed.mesabbah@dit.ie.

SIHAM RAHOUI, M.Sc. is a researcher in $3 \mathrm{~S}$ Group In College of Business- DIT. She joins the $3 \mathrm{~S}$ Group at the end of 2015, she has an Industrial Engineering degree from ESITH Morocco and M.Sc. in Financial Management from Middlesex University London. Her research interests, include Supply chain management, cost management, financial flow, Simulation and Modeling in Supply Chain. siham.rahoui@dit.ie

MOHAMED AF RAGAB, PhD. is a Postdoctoral Researcher in 3S Group, College of Business, DIT, Ireland. He holds a B.Sc. in Industrial Engineering and MBA from the American University in Cairo (AUC), and PhD from DIT for his work on Knowledge Management. Dr. Ragab's work was published in 
a number of International peer-reviews journals and conferences and received a Highly Commended Paper Award for Academic Excellence from Emerald Publishing Group. mohamed.ragab@dit.ie.

AMR MAHFOUZ, PhD. is a lecturer of data analytics and supply chain management in School of Management, College of Business, DIT. He leads Supply Chain Management team in 3S Group.. Dr. Mahfouz has received his PhD in Operations and Supply Chain Management from DIT. He has published several journal and International conference articles in the area of supply chain management, simulation and lean supply chain. His research interest includes lean supply chain, supply chain resilience, simulation applications in business process, and supply chain analytics.amr.mahfouz@dit.ie

AMR ARISHA, Ph.D. is Professor at College of Business, DIT and the Founder/Director of the 3S Group. He received his PhD in Industrial Engineering from Dublin City University (DCU). Intel-Ireland has sponsored his research from 2000 - 2005. His research path is focused on the ultimate goal of developing an integrated solution frameworks leveraging existing mathematical and systems tools from a number of fundamental approaches including system analysis, value stream mapping, stochastic modeling, game theory, simulation and optimization. His work places the quest for operations excellence at the heart of many contemporary challenges in applications such as healthcare, supply-chain management, production scheduling, and teaching/training. He is a member in IIE, IMECH, IEI, ESE, ORS, IEEE and ASME and Chief Examiner at MII. amr.arisha@dit.ie. 